\title{
Cost-effectiveness analysis for sustainable wastewater engineering and water resources management: a case study at Minho-Lima river basins (Portugal)
}

\author{
S. Costa ${ }^{a}$, L. Coutinho ${ }^{a}$, A.G. Brito ${ }^{a^{*}}$, R. Nogueira ${ }^{a}$, A.P. Machado ${ }^{a}$, J.J. Salas ${ }^{b}$, C. Póvoa ${ }^{c}$ \\ ${ }^{a} I B B$ - Institute for Biotechnology and Bioengineering, Centre for Biological Engineering, University of Minho, \\ Campus de Gualtar 4710-057 Braga, Portugal \\ Tel. +351 253604410; Fax+351 253678986; email: agbrito@deb.uminho.pt. \\ ${ }^{b}$ Centre for New Water Technologies (CENTA), Av Américo Vespucio 5-1, Pl. 2 ${ }^{\underline{a}}$ Mód. 10, 41092, Seville, Spain

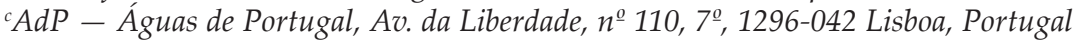

Received 18 April 2008; Accepted in revised form 1 August 2008

\section{A B S T R A C T}

A cost-effectiveness integrated methodology applied in a water resources management and sanitation project in Minho and Lima's region (Portugal) is presented. First, environmental objectives and programmes of measures (PM) are established and priorities are identified using a cause-effect assessment matrix and a global effectiveness index. Aiming to achieve more demanding goals, some complementary actions are considered, including "decentralized low-energy wastewater treatment plants construction". A geographic information system was used to select potential implementation sites, and suitable treatment processes for each location are identified. The centralized and decentralized wastewater treatment plants combination is promising, achieving a cost-effectiveness attendance of $€ 1510$ /equivalent-inhabitant in Minho-Lima river basins.

Keywords: Cost-effectiveness analysis; Sustainable wastewater treatment; Water economics; Water Framework Directive (WFD)

\section{Introduction}

European Water Framework Directive (WFD) establishes a structure for action in the water policy domain, stipulating that water-uses economic analysis must contribute to an appraisal of the most cost-effective combinations of measures required under Article 11 [1]. Therefore, environmental and resource costs and benefits information is needed to design cost-effective measures. Meanwhile, there is a lack of clear specifications and methodologies lack to perform cost-effectiveness assessments at the European level [2]. Therefore, the interregional European project "AQUA - Preliminary Studies for the Water Framework Directive Implementation at the Minho-Lima River Basins" was focused on water services cost recovery and practical cost-effectiveness

\footnotetext{
* Corresponding author.
}

methodologies in order to support strategic priorities towards water resources protection and sanitation goals. In that regard, the potential of energy-saving and smallscale wastewater treatment plants, as complementary actions, was analyzed considering their feasibility in rural areas [3]. Indeed, despite the significant efforts carried out by the local water company, levels of wastewater drainage and treatment are still below the aimed level, mostly because of the dispersed settlements at the Minho and Lima region [4]. Furthermore, several water bodies risk failing good ecological status achievement, within the WFD timescale goals, and all measures that can contribute to overcome derogations should be assessed. Therefore, this communication presents a cost-effectiveness integrated methodology simplified scheme applied as a first screen in the context of Minho and Lima water resources management and sanitation goals (Fig. 1). 


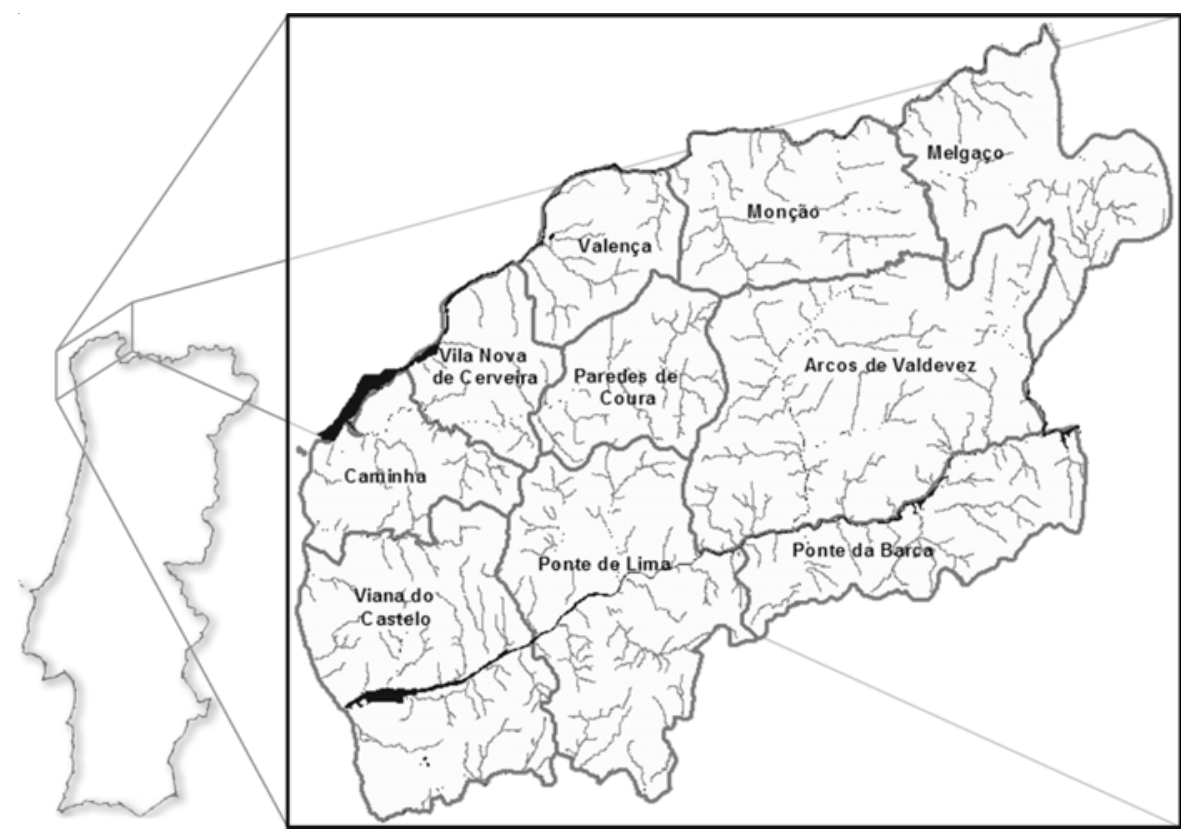

Fig. 1. Minho-Lima river basin study area (Portugal).

\section{Methodology}

This study comprises three interrelated tasks:

(1) Characterization of Minho-Lima river basins and water use trends (considering future scenarios of wastewater treatment levels);

(2) Definition of strategic and operational objectives addressing key thematic areas taking into account a set of environmental indicators according to a PressureState-Response model;

(3) Definition of a programme of measures (PM) based on the existing river-basin management master plans and focused on relevant actions for attaining WFD goals.

After the environmental objectives establishment, high-priority measures definition and complementary actions analysis was performed. This analysis is based on an integrated cost-effectiveness scheme, and Fig. 2 illustrates the methodological design of the comprehensive analysis.

Priorities definition was the cost-effectiveness analysis first level. Inquiring of stakeholders and professionals in order to score options, priorities were selected using a cause-effect assessment matrix and a global effectiveness index (EI), adapted from [5]. Several quality elements defined in the Annex V of WFD were considered in the cause-effect assessment matrix, namely biological, hydromorphological, physical-chemical and socioeconomic elements. The global effectiveness index cal-
Table 1

Criteria for global effectiveness index and related priorities

\begin{tabular}{cll}
\hline EI value range & Effectiveness assessment & Priority \\
\hline $1<\mathrm{EI}<10$ & Low & 1 \\
$11<\mathrm{EI}<20$ & Medium & 2 \\
$21<\mathrm{EI}<30$ & High & 3 \\
\hline
\end{tabular}

culation and priorities criteria are presented in Eq. (1) and Table 1.

$\mathrm{EI}=\sum_{c=1}^{4}\left(\frac{\sum_{i=1}^{n} a_{i}}{n}\right) \times g r_{c}$

where $c$ - quality components ( $c=1$ : biological elements; $c=2$ : hydromorphological elements; $c=3$ : physical-chemical elements; $c=4$ : socioeconomic elements), $a-$ assessment indicators classification for each quality component; $n$ - number of assessment indicators for each quality component: $g r$ - relevance of each quality component.

In order to achieve more demanding quality goals, additional complementary actions for the high-priority measures were then proposed. In that regard, two submethodologies were applied: one based on the analysis of specific cost-effectiveness indicators (targeting the pressures associated with different responses), and an- 


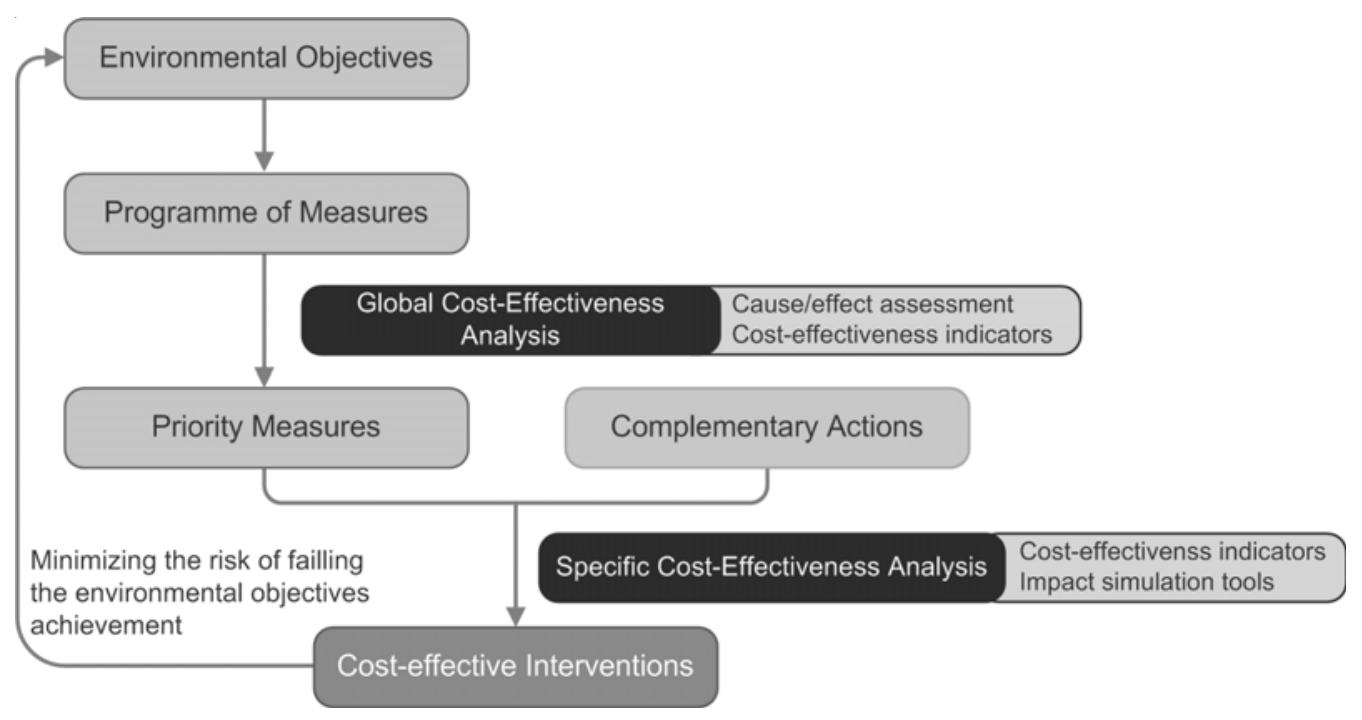

Fig. 2. Integrated cost-effectiveness analysis.

other one based on the environmental impacts assessed by simulation tools [6]. The final step consists of a comparative cost-effectiveness analysis between the PM and the complementary actions value added.

A complementary action "Construction of decentralized low-energy wastewater treatment plants" was assessed in order to increase the wastewater treatment services at rural zones of Minho and Lima's region where centralized wastewaters systems will not be built. A geographic information system was used to cross different characteristics (e.g. climate, water table depth, slope and soil permeability) and sort out a preliminary identification of sites with the best profile for this complementary action, as well as the more appropriate treatment technology to apply in each location. The PM investment requirements were based on the allocated costs derived from the river-basin master plans $[7,8]$. The estimating costs for decentralized wastewater treatment plants are presented in Table 2, and data from equipment suppliers were also collected for such purpose: $€ 1000$ p.e. ${ }^{-1}$ up to 300 p.e.; $€ 750 \cdot$ p.e. $^{-1}$ between 300 and 400 p.e.; $€ 600$ p.e. ${ }^{1}$ between 400 and 500 p.e.; $€ 500$ p.e. ${ }^{-1}$ for more than 500 p.e. Finally, a comparative study of the impact of adding up complementary actions to the selected measures was carried out.

\section{Results and discussion}

Combining WFD goals and water utilities perspectives, Table 3 presents the multi-criteria results arising from the cause-effect matrix and global effectiveness index application. Those results allowed the identification of five "high priority measures" for which complementary actions were defined. Focusing the analysis on the pollutants discharges assessment and control, a complementary action regarding the construction of 10 decentralized

Table 2

Cost functions for decentralized wastewater treatment systems

\begin{tabular}{|c|c|c|c|c|c|c|}
\hline \multirow[t]{3}{*}{ Technology } & \multicolumn{2}{|l|}{ Cost function } & \multirow{3}{*}{$\begin{array}{l}\text { Optimized range } \\
\text { (p.e.) }\end{array}$} & \multirow{2}{*}{\multicolumn{3}{|c|}{$\begin{array}{l}\text { Removal rate } \\
(\%)\end{array}$}} \\
\hline & \multirow{2}{*}{$\begin{array}{l}\text { Construction and } \\
\text { equipment }\end{array}$} & \multirow[t]{2}{*}{ Operation } & & & & \\
\hline & & & & $\mathrm{BOD}_{5}$ & TSS & $\mathrm{P}$ \\
\hline Slow-rate irrigation systems & $y=32.6 \mathrm{e}^{-0,0025 x}$ & $y=5.0 \mathrm{e}^{-0,0019 x}$ & $0-500$ & $90-95$ & $90-95$ & $75-85$ \\
\hline Peat filters & $y=333.1 e^{-0,0002 x}$ & $y=13.2 \mathrm{e}^{-0,0002 x}$ & $1000-2000$ & $80-85$ & 95-99 & $10-30$ \\
\hline Aerated lagoons & $y=131.5 e^{-0,00006 x}$ & $y=20.1 \mathrm{e}^{-0,00003 x}$ & $1500-12000$ & $80-95$ & $70-90$ & $40-60$ \\
\hline Constructed wetlands & $y=371.3 e^{-0,001 x}$ & a.d. & $150-800$ & 98 & 99 & 81 \\
\hline
\end{tabular}

Investment costs: $y$ - Investment cost/Equivalent population (€·p.e. $\left.{ }^{-1}\right) ; x$ - Population (p.e.).

Operation costs: $y$ - Operation cost/ Equivalent population $\left(€ \cdot\right.$ p.e. $\left.{ }^{-1}\right) ; x$ - Population (p.e.). 
S. Costa et al. / Desalination and Water Treatment 4 (2009) 22-27

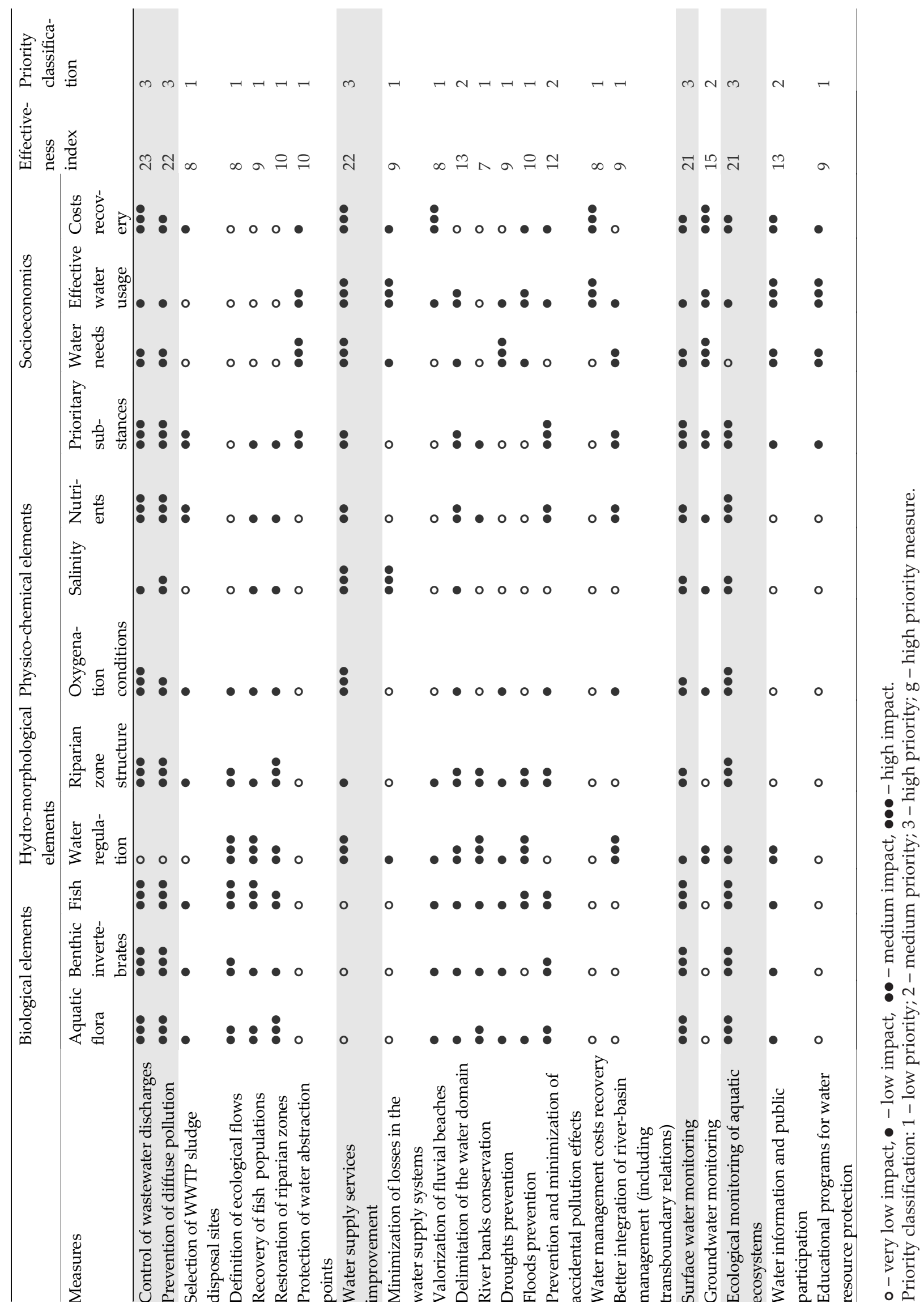




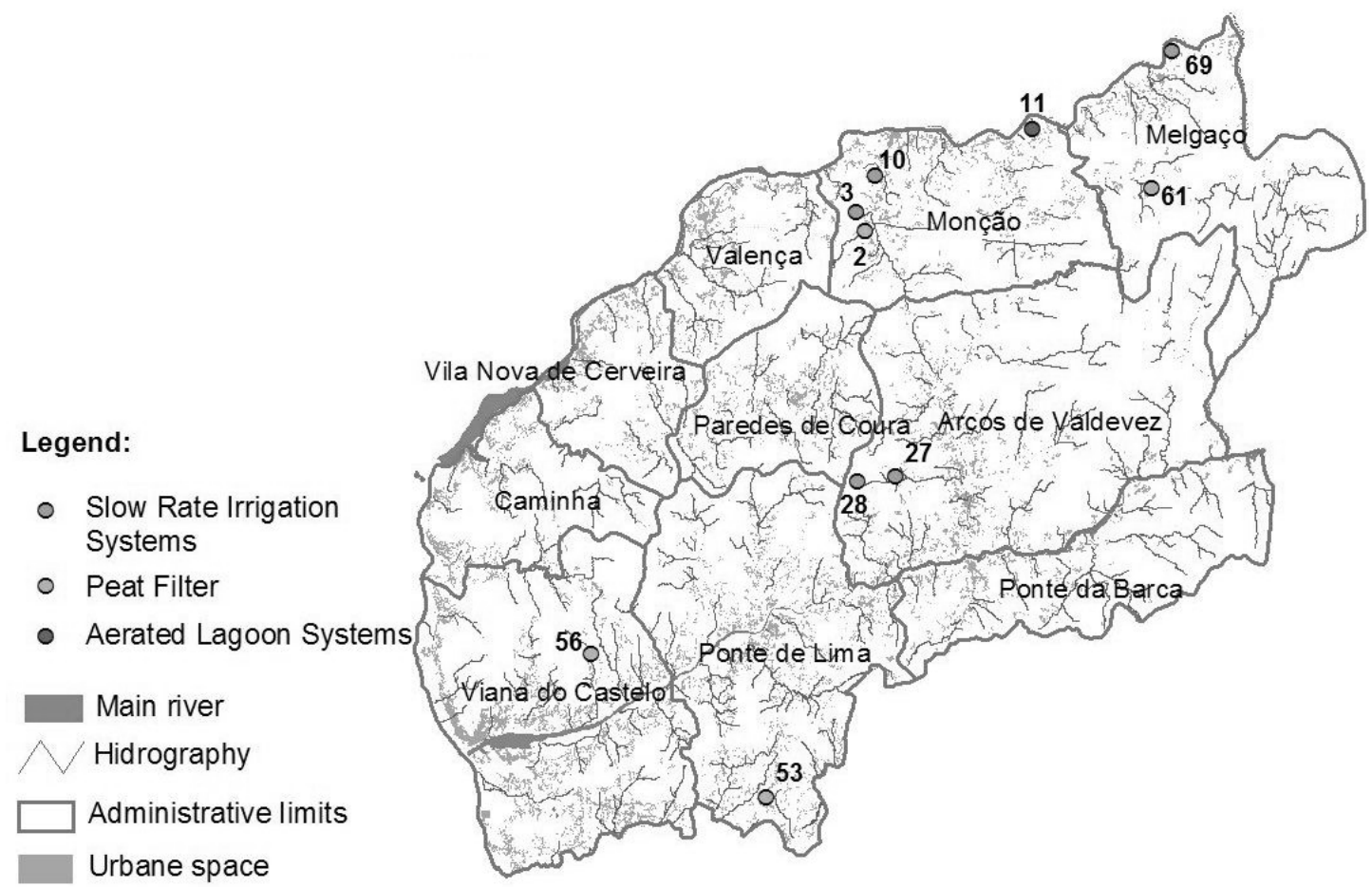

Fig. 3. Potential locations for decentralized low-energy wastewater treatment plants.

low-energy wastewater treatment plants was then set using a cross-comparison between land characteristics and economic criteria. The results are shown in Fig. 3.

The PM implementation without complementary actions will not lead to a substantially different picture in Minho and Lima's region in 2015. Such a business-asusual scenario will not put significant pressure on the water resources on a regional scale (due to the low population density and rural pattern in the areas without wastewater treatment facilities). However, the absence of secondary treatment near water abstraction wells may raise public health risks due to soil and water contamination. Table 4 presents the effectiveness and cost-effec- tiveness indicators for the scenarios with and without the complementary action.

A combination of centralized and decentralized wastewater treatment plants allow a cost-effectiveness attendance of $€ 1510 /$ equivalent-inhabitant. Implementation of such sustainable low-energy wastewater treatment plants (as a complement to the centralized wastewater treatment plants) supports a slightly lower cost-effectiveness relationship when compared to the business-as-usual scenario.

\section{Conclusion}

Cost-effectiveness methodologies can be very useful tools for the PM definition and priorities selection, thus

Table 4

Effectiveness and cost-effectiveness indicators for two scenarios (programme of measures only or with complementary action)

\begin{tabular}{lll}
\hline Implementation costs of complementary actions & $€ 126,400,000$ & \\
\hline Effectiveness indicators (2015) & $(\mathrm{PM})$ & $(\mathrm{PM}+\mathrm{CA})$ \\
Removal of wastewater organic matter $\left(10^{3} \mathrm{~kg} \cdot \mathrm{year}^{-1} \mathrm{BOD}\right)$ & $3820 \mathrm{t} \cdot \mathrm{y}^{-1}$ & $3875 \mathrm{t} \cdot \mathrm{y}^{-1}$ \\
WWTP service upgrade $\%$ of p.e. and p.e.) & $61 \% ; 159826$ p.e. & $64 \% ; 164026 \mathrm{p} . \mathrm{e}$. \\
Cost-effectiveness indicators (2015) & $(\mathrm{PM})$ & $(\mathrm{PM}+\mathrm{CA})$ \\
Removal of wastewater organic matter $(€ \cdot \mathrm{kg}$ BOD removed) & $€ 3.22 \cdot \mathrm{kg}^{-1}$ & $€ 3.17 \cdot \mathrm{kg}^{-1}$ \\
WWTP service upgrade (1000€ per each new inhabitant served) & $€ 1540 \cdot \mathrm{inhab}^{-1}$ & $€ 1510 \cdot \mathrm{inhab}^{-1}$ \\
\hline
\end{tabular}

PM: programme of measures; PM + CA: programme of measures plus complementary action. 
contributing to a better decision-making process. The present work intended to test a practical cost-efficiency methodology, providing qualitative and quantitative results in a first assessment of measures and complementary actions in Minho-Lima river basins, combining WFD and sanitation goals within the context of a regional water services company. The iterative processes that link economic analyses and pressures and impacts analysis should continue in order to move forward cost-effectiveness methodologies.

\section{References}

[1] Directive 2000/60/EC of the European Parliament and of the Council of 23 October 2000, establishing a framework action in the field of water policy.

[2] B. Görlach, A. Raggamby and J. Newcombe, Assessing the costeffectiveness of environmental policies in Europe. Conf. on Impact Assessment for a New Europe and Beyond, University of Manchester, UK, 15-17 June 2005.

[3] A. Machado, L. Urbano, A.G. Brito, P. Janknecht, J.J. Salas and R. Nogueira, Life cycle assessment of wastewater treatment options for small and decentralized communities, Water Sci. Tech., 56 (2007) 3.

[4] Águas do Minho e Lima, S.A. (AdML). Elementos de Base e Dados Económico-Financeiros. Viana do Castelo, 2005.

[5] E. Interwies, R. Kraemer, N. Kranz, B. Görlach and T. Dworak, Basic principles for selecting the most cost-effective combinations of measures for inclusion in the programme of measures as described in Article 11 of the Water Framework Directive. Pub. Federal Environmental Agency, Berlin, Germany, 2004.

[6] A.G. Brito, S. Costa, L. Coutinho and R. Nogueira, Internal report on AQUA project, University of Minho, Braga, 2005.

[7] AGRIPRO AMBIENTE / PROFABRIL / DRENA / HLC / FBO. Plano da Bacia Hidrográfica do Rio Minho, Ministério do Ambiente e do Ordenamento do Território, Instituto da Água, 2000.

[8] HIDRORUMO / HIDRO 4 / PROCESL / PROSISTEMAS. Plano de Bacia Hidrográfica do Rio Lima, Ministério do Ambiente e do Ordenamento do Território, Instituto da Água, Direcção Regional do Ambiente do Norte, 1999. 